\title{
Examination of the relationship between physician shortages and compensation rates in primary care versus other specialties
}

\author{
Avery Michaels, Lesley Clack^$^{\wedge}$ \\ Department of Health Policy and Management, University of Georgia, Athens, GA, USA \\ Contributions: (I) Conception and design: Both authors; (II) Administrative support: Both authors; (III) Provision of study materials or patients: \\ Both authors; (IV) Collection and assembly of data: Both authors; (V) Data analysis and interpretation: Both authors; (VI) Manuscript writing: Both \\ authors; (VII) Final approval of manuscript: Both authors. \\ Correspondence to: Lesley Clack. 100 Foster Rd., Athens, GA 30602, USA. Email: lesley.clack@uga.edu.
}

\begin{abstract}
Background: It is projected that the United States will experience a shortage of 21,100 to 55,200 fulltime equivalent primary care physicians by the year 2032. The shortage has been sparked by the passage of the Patient Protection and Affordable Care Act and has continued to grow due to the United States' aging population, population health initiatives, and physician workload. While primary care physicians are responsible for more than half of all physician office visits in the United States, primary care physicians make up approximately $28 \%$ of the workforce. Recently, research has cited compensation as the primary reason for the shortage of primary care physicians. Primary care physicians have historically made less than physicians who specialize in other disciplines. Over the last 10 years, primary care physician compensation has increased. However, the shortage also continues to increase. The purpose of this research is to determine the relationship between primary care physician demand and compensation, and to compare that relationship with other specialties.
\end{abstract}

Methods: Physician supply and demand data were collected utilizing the Association of American Medical Colleges (AAMC) reports, The Complexities of Physician Supply and Demand. Compensation data was collected utilizing Modern Healthcare's Physician Compensation database.

Results: When analyzing physician compensation with the employment cost index, primary care physician compensation was $1 \%$ higher than projected with inflation. Despite earning more than projected, it was determined that demand has little to no impact on primary care physician compensation.

Conclusions: With more physicians moving towards employment with hospitals and hospital systems, there is an increased need for human resources initiatives. Hospital and hospital systems' human resources departments should develop initiatives that increase pay for primary care physicians such as the standardization of compensation regardless of specialty within a healthcare organization.

Keywords: Physician; primary care; compensation; demand; shortage

Received: 09 December 2020; Accepted: 07 April 2021; Published: 25 December 2021.

doi: $10.21037 /$ jhmhp-20-154

View this article at: http://dx.doi.org/10.21037/jhmhp-20-154

\section{Introduction}

Shortages of physicians, especially those within primary care specialties, are at an all-time high and expected to grow. It is projected that the United States will experience a shortage of 46,900 to 121,900 full-time equivalent (FTE) physicians by the year 2032 (1). The fifth annual study conducted by the Life Science division of IHS Markit for the Association of American Medical Colleges (AAMC), The Complexities of

^ ORCID: 0000-0003-2706-0882. 
Physician Supply and Demand: Projections from 2017 to 2032 (1), also predicts that primary care physicians (PCPs) will account for up to half of the total shortage; resulting in a shortage of 21,100 to 55,200 FTE PCPs by the year 2032 (1). According to the Centers for Disease Control and Prevention's (CDC's) 2016 National Ambulatory Medical Care Survey, PCPs were responsible for $54.5 \%$ of all physician office visits in the United States (2). Additionally, the use of PCPs results in a higher value of care, better access to care, increased life expectancy, and lower health costs $(3,4)$. However, as of 2017 , approximately $28 \%$ of the physician workforce were PCPs (1). This discrepancy between the percentage of PCPs in the workforce and the percentage of care that PCPs are responsible for creates a misalignment.

While compensation has increased recently (5), PCPs are often paid least in comparison to other specialties (6). Between the years 2010-2019, family medicine, internal medicine, and pediatric physicians were the three lowest-paid specialties each year with only two exceptions: psychiatry between the years 2013 and 2015 and neonatology and pathology in 2018 (6). With those exceptions, PCPs remained amongst the fourth and fifth lowest-paid specialties respectively (6). Recently, research has cited payment reform for PCPs is imperative to addressing the shortage (7). These claims regarding compensation and the demand for a physician to specialize in primary care are further supported by the law of supply and demand. The law of supply and demand posits that as demand for a good or service increases, the price for that good or service also increases. Thus, as the demand for PCPs increases, resulting in a greater shortage, compensation should, theoretically, also increase. The purpose of this research is to determine if a relationship exists between the demand of PCPs and the average annual compensation PCPs received between the years of 2010 and 2019. Additionally, the relationship, if any, between demand and compensation amongst PCPs will be compared with those of other specialties between those same years.

The shortage of physicians in the United States is largely due to the United States' healthcare climate as well as the demographics of its workforce and population. First, since the passage of the Patient Protection and Affordable Care Act (ACA) in 2010, during President Obama's administration, the usage and necessity of PCPs has increased. This increase is due to the ACA's inclusion of PCPs to serve as gatekeepers for all health services and specialists (8). This assumption is supported by the notion that prior to the ACA's passage, the United States experienced both shortages and surpluses of physicians (9). Second, the aging population presents the biggest challenge to the demand of physicians, and the problem is twofold. The United States' aging population is growing and demanding more services. By 2032, the total United States' population is projected to grow $10.3 \%$ (1). However, the growth is expected to occur disproportionately across age groups with those under 18 years old projected to grow $3.5 \%$, while those over 65 years old are projected to grow $48.0 \%$ (1). Additionally, the growing aging population is resulting in an increased population of older practicing physicians. In 2018, almost one-third of physicians were 60 or older. Further, according to the United States Census Bureau, by the year 2030, all Baby Boomers will be age 65 or older (10); resulting in those 65 or older outnumbering those under 18 years old for the first time in history, in the year 2034 (11). Third, removing barriers to health care and addressing long-term population health goals will increase the demand for health services. If community-based public health initiatives such as obesity, diabetes, and smoking are addressed, the shortage could increase by 33,900 FTE physicians (1). Finally, physicians of all ages are working less than in years past. If physicians continue on this trend, the shortage could be up to 20,900 FTE physicians greater compared to if those same physicians worked the same hours (1). We present the following article in accordance with the MDAR reporting checklist (available at http:// dx.doi.org/10.21037/jhmhp-20-154).

\section{Methods}

For consistency, supply and demand data were, both, retrieved from the AAMC's The Complexities of Physician Supply and Demand which compiles data from the American Medical Association's (AMA's) Physician Masterfile. The supply and demand within each year is representative of FTE physicians who have completed their graduate medical education (1). The AAMC released its first two reports on physician supply and demand in 2008 and 2010, independently. Since its subsequent report in 2015, the AAMC has published annual updates to its projections with assistance from IHS Markit Ltd. The report, The Complexities of Physician Supply and Demand, projects physician workforce in the United States $10-15$ years into the future. The AAMC's 2008, 2010, and 2015 reports projected workforce through 2025, while the 2016-2018 reports projected through 2030 and its most recent report, 
Table 1 Physician supply

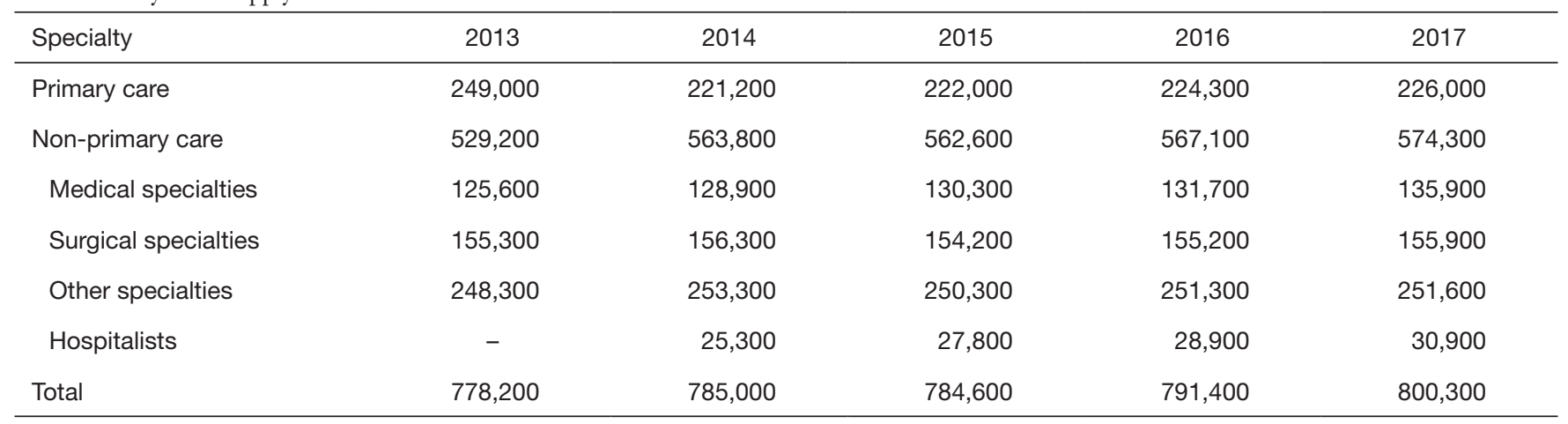

2019, projects through $2032(1,12,13)$

Because The Complexities of Physician Supply and Demand includes actual supply and demand values from 2 years prior to each update and because compensation data was available for the years 2010-2019, only those years were considered for analysis.

Data involving physician compensation was retrieved from Modern Healthcare's Physician Compensation survey which included 2,653 data points by specialty. The 26th annual survey records the average pay for multiple specialties in the United States each year and is available for purchase from Modern Healthcare's website (6). For the purposes of this analysis, compensation is defined as the average pay a physician receives from an employer and not from physicians who operate a private practice.

In order to further examine the relationship between demand and compensation amongst PCPs, demand and compensation amongst PCPs was compared with demand and compensation from additional specialties. According to the AAMC's biennial Physician Specialty Data Report, the specialties of anesthesiology, emergency medicine, and obstetrics and gynecology contained the largest numbers of active physicians, excluding specialties considered to be primary care, in each of the last four reports since 2010, except for the years 2010 and 2013 in which psychiatry surpassed emergency medicine (14-17). Utilizing the data sources described, the physician shortage for PCPs and physicians specializing in anesthesiology, emergency medicine, and psychiatry and compensation with consideration for the employment cost index (ECI) were projected. These projections were assessed to determine if a relationship exists between PCP demand and compensation, and to compare that relationship, if any, with other specialties.

\section{Statistical analysis}

\section{Physician supply}

Physicians were considered PCPs if their self-designated specialty was adolescent medicine, family medicine, family practice, general practice, geriatric medicine, geriatric medicine/family practice, internal medicine, internal medicine/geriatric medicine, internal medicine/pediatrics, or pediatrics (1).

Physicians were considered non-primary care if they specialized in anything other than PCPs specialties. Within non-primary care, physicians were categorized as medical specialties, surgical specialties, other specialties, and hospitalists. Physicians were considered medical specialties if they specialized in allergy and immunology, cardiology, critical care, dermatology, endocrinology, gastroenterology, hematology and oncology, infectious diseases, neonatal and perinatal medicine, nephrology, pulmonology, and rheumatology. Physicians were considered surgical specialties if they specialized in general surgery, colorectal surgery, neurological surgery, obstetrics and gynecology, ophthalmology, orthopedic surgery, otolaryngology, plastic surgery, thoracic surgery, urology, vascular surgery, and other surgical specialties. Physicians were considered other specialties if they specialized in anesthesiology, emergency medicine, neurology, pathology, physical medicine and rehabilitation, psychiatry, radiology, and all other specialties. Hospitalists are those that have specialized in adult primary care but were not categorized within the primary care category (1) (see Table 1).

\section{Physician shortage}

While the supply of PCPs has increased, the demand for PCPs has also increased and at a higher rate; resulting in a shortage. Physicians were categorized as either primary care 
Table 2 Physician shortage

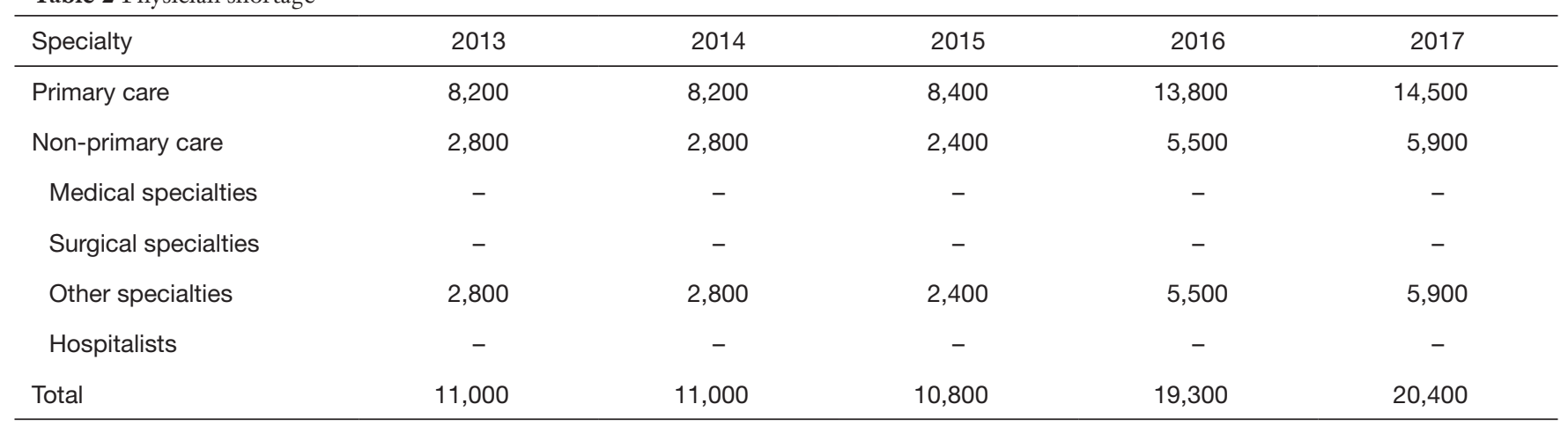

Table 3 Active physicians in anesthesiology, emergency medicine, and psychiatry

\begin{tabular}{|c|c|c|c|c|c|c|}
\hline Specialties & 2013 & 2014 & 2015 & 2016 & 2017 & Average \\
\hline Emergency medicine & $10.0 \%$ & - & $10.2 \%$ & - & $10.6 \%$ & $10.1 \%$ \\
\hline Psychiatry & $10.0 \%$ & - & $09.8 \%$ & - & $09.5 \%$ & $10.0 \%$ \\
\hline
\end{tabular}

or non-primary care; with non-primary care being specified as medical, surgical, or other specialties, and hospitalists. Physicians categorized as other specialties accounted for the total FTE shortage amongst all non-PCPs.

While physicians specializing in obstetrics and gynecology surpassed psychiatry in terms of the number of active physicians within the AAMC's biennial Physician Specialty Data Report (14-17), obstetrics and gynecology is considered a surgical specialty (1). Because only other specialties contained shortages, only specialties considered to be other specialties could be used for comparison. Thus, the specialty of obstetrics and gynecology was replaced by psychiatry in the analysis (see Table 2).

In order to establish the shortage for physicians specializing in anesthesiology, emergency medicine, and psychiatry, the number of physicians in each specialty reported in the Physician Specialty Data Report and The Complexities of Physician Supply and Demand reports were utilized. From the number of physicians in each specialty and the supply of physicians in the other specialties category, a proportion was established. The proportion of physicians specializing in anesthesiology, emergency medicine, and psychiatry each year were calculated. These proportions were then used to estimate the shortage within each specialty. supply was missing for a particular year, the average proportion across all years was used instead (see
Table 3).

\section{Physician compensation (Figure 1)}

The Modern Healthcare's Physician Compensation database compiles average physician compensation utilizing an annual survey distributed to ten physician placement firms. The database houses physician compensation reported by each firm and for each year between the years of 2010-2019, as well as the average compensation across 23 specialties: anesthesiology, invasive and noninvasive cardiology, dermatology, emergency medicine, family practice, gastroenterology, general surgery, hospitalist, intensivist, internal medicine, neonatology, neurology, obstetrics/gynecology, oncology (including hematology), orthopedic surgery, pathology, pediatrics, plastic surgery, psychiatry, radiation oncology, radiology, urology (6).

From the specialties included within the survey, only those from specialties of family practice, internal medicine, and pediatrics were considered PCPs. While the database provided physician compensation from multiple firms for each year, four of those firms consistently provided complete physician compensation data for each year and for each specialty used for this analysis; with the exception of compensation reported by The Medicus Firm for the specialty of Anesthesiology for the years 2018 and 2019. Those four firms were the American Medical Group 


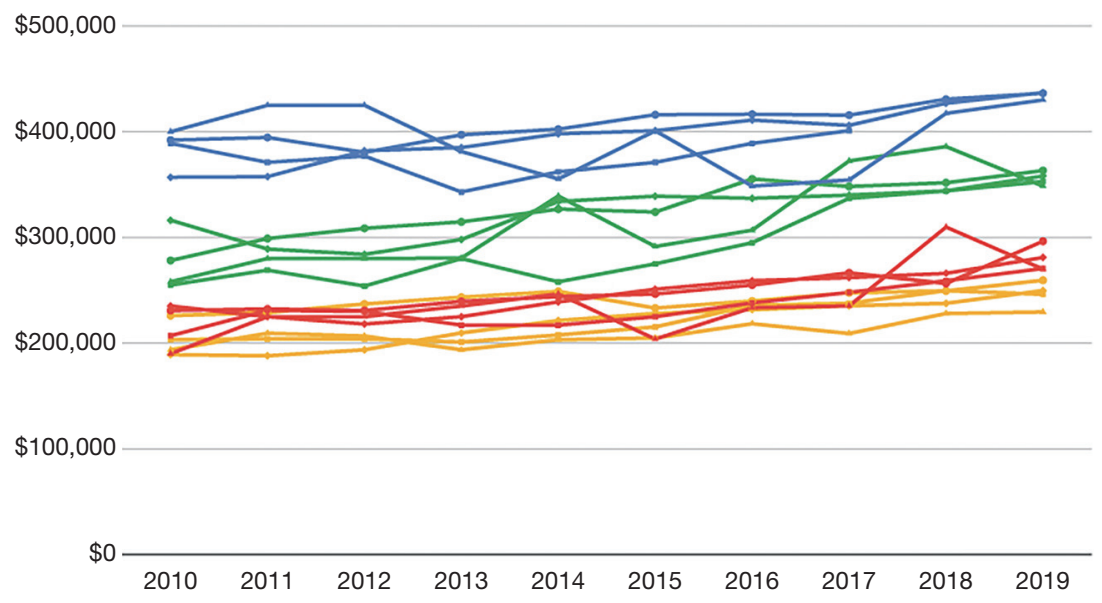

Figure 1 Physician compensation from the years 2010 to 2019. Compensation was separated by specialty and the firm from which compensation was reported. Specialty is indicated by color; primary care—yellow, anesthesiology—blue, emergency medicine-green, and psychiatry—red. Firms are indicated by shape; American Medical Group Association—circle, The Medicus Firm—square, Pinnacle Health Group-triangle, and Pacific Companies—diamond.

Table 4 Annual ECI 2010-2019

\begin{tabular}{lc}
\hline Year & $E C I$ \\
\hline 2010 & 0.016 \\
2011 & 0.021 \\
2012 & 0.019 \\
2013 & 0.017 \\
2014 & 0.017 \\
2015 & 0.020 \\
2016 & 0.020 \\
2017 & 0.029 \\
2018 & 0.024 \\
2019 & - \\
\hline
\end{tabular}

$\mathrm{ECl}$, employment cost index.

Association, The Medicus Firm, Pinnacle Health Group, and Pacific Companies (6).

Compensation for PCPs was consistently the lowest compared to the average compensation of anesthesiology, emergency medicine and psychiatry. Compensation for physicians specializing in anesthesiology was consistently the highest; followed by emergency medicine and psychiatry.

In order to determine if the increase in compensation was due to the shortage or increased demand of each specialty, compensation was adjusted for inflation using the
U.S. Bureau of Labor Statistics' ECI. The ECI records the changes in labor costs incurred by organizations. These costs reflect total compensation, including wages and benefits, for a particular field (18). For the purposes of this analysis, ECI was reviewed for Civilian Workers in the Health Care and Social Assistance Sector. This designation and sector were chosen as Civilian Workers includes private industry as well as state and local governments. The Health Care and Social Assistance sector was chosen as it includes ambulatory health services, hospitals, nursing and residential care facilities, and social assistance subsectors $(19,20)$ (see Table 4).

\section{Results}

\section{Demand}

Anesthesiology, emergency medicine, and psychiatry averaged $9.5-10.9 \%$ of the shortage of physicians within the other specialties and $2.17-3.0 \%$ of the total shortage in any given year. Whereas PCPs accounted for $71.1-77.8 \%$ of the total shortage in any given year (see Table 5).

\section{Compensation (Figure 2)}

The ECI, from 2010 to 2019, has fluctuated between 1.6\% and 2.9\%; each year. Accounting for ECI, compensation for each year was adjusted. Beginning with compensation in the year 2010, and projecting compensation for the next 
Table 5 Shortage of physicians in primary care, anesthesiology, emergency medicine, and psychiatry

\begin{tabular}{|c|c|c|c|c|c|}
\hline Specialty & 2013 & 2014 & 2015 & 2016 & 2017 \\
\hline Non-primary care & 2,800 & 2,800 & 2,400 & 5,500 & 5,900 \\
\hline Other specialties & 2,800 & 2,800 & 2,400 & 5,500 & 5,900 \\
\hline Anesthesiology & 306 & 306 & 257 & 595 & 615 \\
\hline Psychiatry & 280 & 280 & 234 & 550 & 562 \\
\hline Total & 11,000 & 11,000 & 10,800 & 19,300 & 20,400 \\
\hline
\end{tabular}

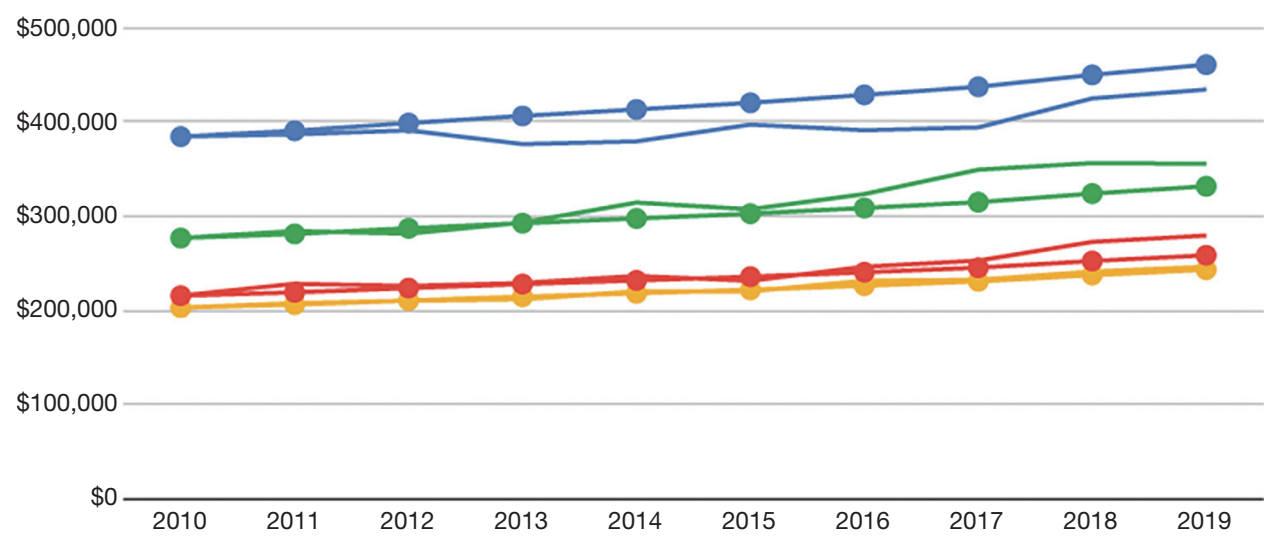

Figure 2 Physician compensation compared to physician compensation with employment cost index (ECI). Compensation was separated by specialty and compensation type. Specialty is indicated by color; primary care-yellow, anesthesiology-blue, emergency medicine-green, and psychiatry—red. Compensation type is indicated by shape; actual compensation—straight line and projected income with ECI—circle.

year, PCPs and physicians in emergency medicine and psychiatry earned more at the end of the ten-year period. While physicians in emergency medicine and psychiatry each earned 7\% more in 2019 than they were projected to earn using compensation in 2010 and annual ECIs, PCPs earned the closest to their projected earnings with earning $1 \%$ more than projected. Only physicians in anesthesiology earned less than projected with $6 \%$ less.

\section{Discussion}

\section{Compensation}

In examining physician compensation, specifically amongst PCPs, compensation has increased. However, when controlling for ECI, compensation for PCPs is $1 \%$ higher than the projected if compensation had actually followed inflation trends. While an increase in workload may also contribute to an increase in compensation, previous research suggests that workload has decreased for physicians. According to the Medical Group Management Association's 2018 MGMA DataDive Provider Compensation report, physician workloads have remained the same despite increases in compensation (21). Further, physicians are seeing less patients. The year 2018 marked the first time in which employed physicians surpassed those that have an ownership stake in their practice (22). The decrease in ownership stake has also resulted in a decrease in productivity. Employed physicians see 19\% fewer patients compared to those with an ownership stake (23).

Given that workload did not increase and PCP compensation was $1 \%$ higher than projected with inflation, it is reasonable to assume that the demand or the shortage of PCPs has little to no impact on the compensation that PCPs received in any given year and compensation is 
influenced by inflation.

\section{Sample}

The compensation data utilized in this research didn't offer location data nor did it account for all physicians in the United States. Only physicians that used the consulting firms were included in the database. The sample of physicians that used the physician placement firms, may have been small samples resulting in averages not representative of the whole. Additionally, certain specialties may be more likely to use physician placement firms.

Whereas rural and urban areas do not provide much effect on physician compensation, the state in which the physician practices does (24). Over the past 5 years, the median physician compensation has decreased for some specialties up to nine percent while some states experienced an increase up to $41 \%$. The changes in compensation within specific states has resulted in physician compensation, depending on specialty, ranging between $\$ 100,000$ and $\$ 270,000$ per year (21).

\section{Shortage}

Previous research cited that prior to the ACA, the United States experienced both shortages and surpluses of physicians in any given year. However, prior to the ACA, demographics of the United States' population were different. The differences in the United States' population, specifically with the aging population, could be responsible for the discrepancy.

In examining the compensation, perhaps it is an initial gap in compensation that has perpetuated the lack of compensation. This claim is further supported by the evidence suggesting that average yearly compensation for PCPs most closely follows the ECI and that the demand for PCPs has little to no impact on compensation.

\section{Closing the gap}

PCPs in private practice have declined. This decline is, in large, due to reimbursements, particularly with Medicare, and administrative and overhead costs (25). With an increasing number of PCPs transitioning from private practice to employment with hospitals and hospital systems, there is an increased need for human resources and hiring to address inequities in compensation for physicians who choose to practice in specialties that historically pay less; specifically those considered primary care. Perhaps the implementation of programs such as standardized compensation for all practicing physicians within the healthcare organization will encourage more physicians to practice in primary care specialties.

Physician workload and compensation and workload have been significantly affected by the COVID-19 pandemic. According to the consulting firm, Kaufman Hall, physician net revenue declined $4.5 \%$ in 2020 compared to 2019 as the industry struggled with declines in patient volumes due to the COVID-19 pandemic (26). Future research should specifically examine the effects of reduced workload on physician compensation as a result of the COVID-19 pandemic.

\section{Conclusions}

Since the passage of the ACA in 2010, the United States has experienced an increasing shortage of physicians; specifically those considered PCPs. Given the United States' demographics, PCP shortages are projected to continue increasing into the year 2032. Despite increases in the use of PCPs, PCPs remain amongst the lowest-paid in comparison to other specialties. Recent research suggests that this lack of compensation is the primary reason for the shortage. On average, PCPs earn 1\% more than they are projected to according to the ECI between the years 2010 and 2019, which suggests that the shortage of PCPs has little to no effect on the average compensation they receive. With the increasing number of physicians moving from private practice to employed physicians, the importance of human resources and hiring initiatives is growing. Human resources departments must implement initiatives that will increase compensation for PCPs and positively impact the shortage. Initiatives such as standardizing pay for all physicians within the healthcare organization can be an effective method to do so.

\section{Acknowledgments}

Funding: None.

\section{Footnote}

Reporting Checklist: The authors have completed the MDAR reporting checklist. Available at http://dx.doi.org/10.21037/ jhmhp-20-154

Conflicts of Interest: Both authors have completed the 
ICMJE uniform disclosure form (available at http:// dx.doi.org/10.21037/jhmhp-20-154). The authors have no conflicts of interest to declare.

Ethical Statement: The authors are accountable for all aspects of the work in ensuring that questions related to the accuracy or integrity of any part of the work are appropriately investigated and resolved.

Open Access Statement: This is an Open Access article distributed in accordance with the Creative Commons Attribution-NonCommercial-NoDerivs 4.0 International License (CC BY-NC-ND 4.0), which permits the noncommercial replication and distribution of the article with the strict proviso that no changes or edits are made and the original work is properly cited (including links to both the formal publication through the relevant DOI and the license). See: https://creativecommons.org/licenses/by-nc-nd/4.0/.

\section{References}

1. Association of American Medical Colleges. The Complexities of Physician Supply and Demand: Projections from 2017 to 2032. Association of American Medical Colleges; 2019 [cited Feb 21, 2020]. Available online: https://www.aamc.org/system/files/c/2/31-2019_ update_-_the_complexities_of_physician_supply_and_ demand_-_projections_from_2017-2032.pdf

2. National Center for Health Statistics; [cited Apr 21, 2020]. Available online: https://www.cdc.gov/nchs/data/ahcd/ namcs_summary/2016_namcs_web_tables.pdf

3. Levine DM, Landon BE, Linder JA. Quality and Experience of Outpatient Care in the United States for Adults with or Without Primary Care. JAMA Intern Med 2019;179:363-72. Erratum in: JAMA Intern Med. 2019 May 1;179(5):733. doi: 10.1001/jamainternmed.2019.0618. JAMA Intern Med. 2019 Jun 1;179(6):854. doi: 10.1001/ jamainternmed.2019.1010.

4. Basu S, Berkowitz SA, Phillips RL, et al. Association of Primary Care Physician Supply With Population Mortality in the United States, 2005-2015. JAMA Intern Med 2019;179:506-14.

5. Darves B. Recruiting Physicians Today. [cited Apr 21, 2020]; Available online: http://employer.nejmcareercenter. org/rpt/RecruitingPhysiciansToday_MayJune17.pdf

6. Physician Compensation: 2019. [Data file]. Modern Healthcare; 2019. [cited Apr 21, 2020]. Available online: https://www.modernhealthcare.com/data-lists/40298/ physician-compensation-2019

7. Zabar S, Wallach A, Kalet A. The Future of Primary Care in the United States Depends on Payment Reform. JAMA Intern Med 2019;179:515-6.

8. Patient Protection and Affordable Care Act of 2010, H.R. 3590, 111th Cong. 2010.

9. Jacobson PD, Jazowski SA. Physicians, the Affordable Care Act, and primary care: disruptive change or business as usual? J Gen Intern Med 2011;26:934-7.

10. United States Census Bureau. Older People Projected to Outnumber Children for First Time in U.S. History. United States Census Bureau; 2018 [cited Feb 21, 2020]. Available online: https://www.census.gov/newsroom/pressreleases/2018/cb18-41-population-projections.html

11. United States Census Bureau. 2020 Census Will Help Policymakers Prepare for the Incoming Wave of Aging Boomers. United States Census Bureau; 2019 [cited Feb 21, 2020]. Available online: https://www.census.gov/ library/stories/2019/12/by-2030-all-baby-boomers-willbe-age-65-or-older.html

12. Association of American Medical Colleges. The Complexities of Physician Supply and Demand: Projections from 2015 to 2030. Association of American Medical Colleges; 2019 [cited Feb 21, 2020]. Available online: https://aamc-black.global.ssl.fastly.net/production/ media/filer_public/a5/c3/a5c3d565-14ec-48fb-974b99fafaeecb00/aamc_projections_update_2017.pdf

13. Association of American Medical Colleges. The Complexities of Physician Supply and Demand: Projections from 2013 to 2025. Association of American Medical Colleges; 2019 [cited Feb 21, 2020]. Available online: https://www.researchgate.net/publication/331556082_ The_Complexities_of_Physician_Supply_and_Demand_ Projections_from_2013_to_2025_Final_Report_ Association_of_American_Medical_Colleges

14. Association of American Medical Colleges. 2018 Physician Specialty Data Report. Association of American Medical Colleges; 2018 [cited Feb 21, 2020]. Available online: https://www.aamc.org/media/35206/download

15. Association of American Medical Colleges. 2016 Physician Specialty Data Report. Association of American Medical Colleges; 2016 [cited Feb 21, 2020]. Available online: https://www.aamc.org/media/8356/download

16. Association of American Medical Colleges 2014 Physician Specialty Data Report. Association of American Medical Colleges; 2014 [cited Feb 21, 2020]. Available online: https://www.aamc.org/system/files/reports/1/2014physicia nspecialtydatabook.pdf 
17. Association of American Medical Colleges. 2012 Physician Specialty Data Report. Association of American Medical Colleges; 2012 [cited Feb 21, 2020]. Available online: https://www.aamc.org/media/33486/download

18. U.S. Bureau of Labor Statistics; 2020 [cited Apr 21, 2020]. Available online: https://www.bls.gov/web/eci/ echistrynaics.pdf

19. Glossary. U.S. Bureau of Labor Statistics. U.S. Bureau of Labor Statistics; 2016 [cited Apr 21, 2020]. Available online: https://www.bls.gov/bls/glossary.htm

20. Health Care and Social Assistance: NAICS 62. U.S. Bureau of Labor Statistics. U.S. Bureau of Labor Statistics; 2016 [cited Apr 21, 2020]. Available online: https://www. bls.gov/iag/tgs/iag62.htm

21. Medical Group Management Association; [cited Apr 21, 2020]. Available online: https://www.mgma.com/pressreleases/new-mgma-provider-compensation-data

22. Kane C. Updated Data on Physician Practice Arrangements: For the First Time, Fewer Physicians are Owners than Employees. American Medical Association; [cited Apr 21, 2020]. Available online: https://www. ama-assn.org/system/files/2019-07/prp-fewer-owners-

doi: 10.21037/jhmhp-20-154

Cite this article as: Michaels A, Clack L. Examination of the relationship between physician shortages and compensation rates in primary care versus other specialties. J Hosp Manag Health Policy 2021;5:41. benchmark-survey-2018.pdf

23. The Physicians Foundation. The Physicians Foundation 2016 Physician Survey. The Physicians Foundation; 2016 [cited Apr 21, 2020]. Available online: https:// physiciansfoundation.org/press-releases/the-physiciansfoundation-2016-physician-survey/

24. Darves B. Demystifying Urban Versus Rural Physician Compensation. NEJM Career Center [cited Apr 21, 2020]; Available online: https://www.nejmcareercenter. org/article/demystifying-urban-versus-rural-physiciancompensation

25. Jackson Healthcare. Physicians Continue to Leave Private Practice for Employment. Jackson Healthcare; 2018 [cited Apr 21, 2020]. Available online: https:// physiciansfoundation.org/press-releases/the-physiciansfoundation-2016-physician-survey/

26. King R. Physician Compensation Slides after COVID-19 Slams Practices. Fierce Healthcare [cited Mar 12, 2021]; Available online: https://www.fiercehealthcare.com/ practices/kaufman-hall-physician-revenue-down-4-52020-as-covid-19-slams-practices 